\title{
Makabagong istratehiya sa pagtuturo ng akademikong Filipino: Pagsilip sa bagong kadawyan
}

Gile, Ianne

Veritas College of Irosin, Philippines

Certiza, Melbert

Veritas College of Irosin, Philippines

Medez, Mia

Veritas College of Irosin, Philippines

Aniag, Elizabeth

Veritas College of Irosin, Philippines

Gelilio, Eric

Veritas College of Irosin, Philippines

Sorsogon State University, Philippines

Gallanosa National High School, Philippines (gelilioeric@gmail.com)

$\begin{array}{lll}\text { Received: } 30 \text { January } 2022 & \text { Revised: } 5 \text { February } 2022 & \text { Accepted: } 7 \text { February } 2022 \\ \text { Available Online: } 7 \text { February } 2022 & \text { DOI: } 10.5861 / \text { ijrse.2022.137 } & \end{array}$

\section{Abstract}

In abundance of the pandemic, it had a major impact that signaled various methods to promote education, including modern strategies for teaching Filipino academia; peek into the new kadawyan, in elementary and secondary. Quantitative research was used to identify modern strategies in teaching academic Filipino, and to express the perseverance of teachers to be able to share quality education with students despite the obstacles posed by pandemic and technical problems in modern technology and even the ever-changing offerings of local and national laws and regulations related to health protocols in response to the health care of the Filipino people. According to the DOH, there are Health Protocols that we must follow to prevent the said COVID-19 which has caused major changes in our society. To discover and share the importance and usefulness of innovative strategies, the researchers used a Google form to disseminate a survey to be able to compile and analyze and continuously determine what the innovative teaching strategies really are. academic Filipino. Each result shows that of the 15 elementary and secondary teachers, each teacher has his or her own method of promoting the implementation of education despite the pandemic. The modular method of learning the lessons has $(0.9 \%)$ indicating that it is one of the more effective strategies in teaching academic Filipino. Lack of equipment (1.05\%) stated that it affects teaching. In presenting the problem, wants to expand more and give enough attention and focus to the methods that should be performed properly to make it easier for each student and teacher to learn in the time faced by the majority.

Keywords: modular learning lessons, lack of equipment, strategies, Filipino, new normal 


\section{Makabagong istratehiya sa pagtuturo ng akademikong Filipino: Pagsilip sa bagong kadawyan}

\section{Introduksyon}

Ang dumaragsang suliraning dulot ng pandemya ay nakakalungkot isipin na maaaring maraming kabataan ang mapag-iiwanan na sa edukasyon, sapagkat hindi lahat ng mag-aaral ay may kakayanan na mapunan ang mga pangangailangan sa mga panibagong pamamaraan ng pag-aaral. Tunay na nahihirapan ang lahat sa makabagong istratehiya sa pagtuturo ngunit hindi ito naging balakid ang pandemya upang sumuko ang mga guro at mga kagawaran ng edukasyon (Chin et al., 2022). Kung kaya’t sa gitna ng mga suliraning humahadlang na maisulong ang edukasyon, nagpahayag ng pakiki-isa ang Kagawaran ng Edukasyon sa sambayanang Pilipino laban sa pandemya. Buong katapatan na ipinangako ang pagsisikap at paglaan ng sapat na oras at pagbabahagi ng kasanayan ang Kagawaran ng Edukasyon bilang buong suporta sa adhikain ng gobyerno na mapahilom ang ating bansa. Bukod pa rito ay naglunsad ng isang komprehinsibong "Learning Continuity Plan" na tutugon sa mga hamon kabilang ang mga pagsasaayos sa kurikulum, pagkakahanay ng mga materyales sa pagkatuto, at karampatang suporta para sa mga guro at magulang (Departmen of Education, 2020).

Ayon kay Evangelista (2012), kailangan may sapat na kasanayan sa pag iisip at pakikinig sa nagsasalita o pagkatuto base sa naririnig; ngunit dahil sa pandemyang dinaranas natin malimit ang access sa pagturo ng tradisyunal na pag aaral dahil modyular at birtuwal lamang ang estratihiya ng pagturo ng mga guro. Kaugnay na Pag aaral tungkol sa etratihiya ng pagtuturo sa akademikong filipino, ang ginagampanan ng teknolohiya sa paghabi ng kultura, lalo na sa kabataan. Ang kulturang popular ay nakabatay sa pagdisimina ng iba't ibang bagay gamit ang isang midyum. Hindi natin maikakaila na ang Internet ay isang penomena na naging kaakibat ng isang makabagong kultura (Boroidan et al., 2020).

Sa bawat henerasyon ng makabagong teknolohiya ay maraming kahalagahan ang naiaambag nito sa pamumuhay ng tao sa pang-araw-araw. Hindi maipagkakaila na ang mga Social Networking Sites ay isa sa naging produkto ng makabagong panahon dahil napapabilis nito ang komunikasyon. Ang komunikasyon ay isang makabuluhang kasangkapan] upang maangkin ng bawat nilikha at ang kakayahang maipaliwanag nang buong linaw ang iniisip at nadarama. Dito kusang umuusbong ang isang matatag na pagkakaunawaan (De Torres et al., 2022). Ayon sa learning community plan (2020-2021) Upang matiyak na magagawa ng mga mag-aaral ang kanilang mga gawain sa paaralan, gumagamit ng Google Suite for Education na nagbibigay mga tool sa pakikipagtulungan (Gmail, Meet, Hangouts), Mga tool sa pagsulat ng dokumento (Sheets, Docs), Productivity resources (Drive, Calendar) at higit pa.

Kaya't nararapat lamang na ang mga guro at mga magulang habang kaagapay ang sangunian ng pamahalaan ay nagkakaisa na maitaguyod ang dekalidad na pagkatuto sa edukasyon ng mga mag-aaral alang-alang sa kaunlaran at pagpapakitang kahalagahan ng isang mag-aaral sa kinasasangkutan niyang lipunan. Ang pananaliksik na ito ay naglalayon na matukoy ang mga pagsubok na kinakaharap at mga kaparaanan na ginagamit upang maisakatuparan ang makabagong istratehiya sa pagtuturo ng akademikong Filipino: Pagsilip sa bagong kadawyan. Layunin din na matuklasan ang kahalagahan at kapakinabangan ng ang makabagong istratehiya sa pagtuturo ng akademikong Filipino: Pagsilip sa bagong kadawyan.

\subsection{Paglalahad ng suliranin}

Ano-ano nga ba ang mga estratihiyang ginagamit ng ating mga guro sa pagtuturo sa akademikong Filipino ngayong nagkaroon ng mga pagbabawal sa aktuwal na pakikipagtunghayan sa pagitan ng guro at mga mag-aaral? Paano nga ba ito naisasagawa at gaano ito ka-epektibo? Ang mga ito ay mahalagang malaman ng mga mag-aaral at mga magulang upang higit na maunawaan ang mga kaparaanan na hinahain ng mga guro upang higit na 
mapabuti ang kanilang pagbabahagi ng kasanayan at kalaman sa mga mag-aaral gayon din ay maihayag ang kanilang masugid na pagsusumikap na mapunuan ang lahat ng pangangailangan sa angkop na edukasyon higit sa lahat sa mahigpit at mahirap na panahon ng pandemya. Ang mga sumusunod ay ang mga katanungang naihanda upang matukoy ang suliraning kailangang matugunan ng kapahayagan:

$>\quad$ Ano-ano ang mga makabagong istratehiya sa pagtuturo sa akademikong Filipino sa mga sumusunod na antas? Elementarya at sekundarya?

$>\quad$ Ano-ano ang mga salik na nakakaapekto sa pagtuturo sa akademikong Filipino sa mga sumusunod na antas? Elementarya at sekundarya?

$>\quad$ Ano ang rekomendasyong nabuo batay sa pag-aanalisa at resulta ng mga datos?

Ang kahalagahan ng mga kasagutan sa mga suliraning ito ay makakatulong sa mga mag-aaral na maunawaang lubos ang mga kaparaan ng makabagong istratehiya sa pagtuturo, upang magkaroon ng kalinawan sa isipan sa pamamaraan ng pagpapakilala o pagpapaunawa sa mga pagbabagong pamamaraan ng ating edukasyon sa lipunan dahilan sa mga paghihigpit at pagkakaroon ng mga bagong regulasyong pampubliko na dulot ng pag-iingat sa pang kalusugan laban sa dinadanas na pandemya at upang maging pamilyar ang mga mag-aaral sa mga saliw na inihahanda ng mga guro sa mga aktibidad na pang akademiko. Kapak-pakinabang din sa ating mga guro ang resulta sa pagsisiyasat ng pag-aaral na ito upang matugunan ng kasagutan ang suliranin at masalamin ang mga dapat pang pag-ibayuhin sa mga estratihiya ng pagtuturo kung ito ba ay epektibo, may labis o may pagkukulang pa ng aba sa kanilang mga inihahandang mga pamamaraan ng paghahatid ng makabuluhang edukasyon.

\section{Pamaraang ginamit}

Bilang sangguni at pakikipag-isa sa local na pamahalaan minabuti namin na sumunod sa nakahaing protokol ukol sa proteksyong pangkalusugan kung kaya't aming pinalawig ang pagamit sa iba't-ibang pamamaraan ng pananaliksik na makakapag-ingat ng kalusugan sa pagitan ng mga mag-aaral at mga gurong kalahok at ito ang mga sumusunod na kaparaanang nagawa:

$>\quad$ Paggamit ng internet/google search engine upang makabuo ng ideya na gagabay sa pagkumpuni ng araling ito.

$>\quad$ Paggamit ng E-form upang maisagawa ang online na pakikipagpanayam sa mga gurong kalahok

$>\quad$ Paggawa ng liham pahintulot sa mga gurong personal na makakapanayam

$>\quad$ Paggamit ng produktong teknolohiya katulad ng cellphone at computer

\section{Mga natuklasan}

Mga makabagong istratehiya na natuklasan na ang mga guro mismo ay nakipag-isa na makapagbahagi ng kaalaman sa mga kapwa guro, mag-aaral, at mga magulang sa kung ano-ano nga ba ang mga makabagong istratehiya ang kanilang isinagawa upang maisakatuparan ang paglilingkod sa mga mag-aaral sa kabila ng pandemyang ating kinakaharap.

Ang mga guro at mga ka-agapay ng departamento ng edukasyon ay mas naging mapamaraan upang patuloy na maitaguyod ang paglilingkod kahit na malaki ang pagbabago sa pamamaraan ng pag-aaral ngayong may kinakaharap na COVID-19. Makikita sa resulta na may kani-kaniyang pamamaraan ang mga guro upang patuloy na makapaglingkod at maisalba ang edukasyon sa kabila ng pagsubok na kinakaharap ng nakakarami. Isa sa mga makabagong estratehiya na pilit isinsagawa ng mga guro na makikita sa talahanayan 1 na mayroong pinakamataas o pinaka-maraming sumang-ayon, ito ay ang modyular na pamamaraan ng pag-aaral sa mga aralin para sa pagtuturo sa akademikong filipino kung saan ang mga mag-aaral ay binibigyan ng printed modules kung 
Gile, I., Certiza, M., Medez, M., Aniag, E., \& Gelilio, E.

saan nakapaloob ang mga gawain, o aktibidad na gagawin ng mga mag-aaral sa loob ng isang lingo o higit pa.

\section{Talahanayan 1}

Mga makabagong istratehiya sa pagtuturo ng akademikong Filipino

\begin{tabular}{lcc}
\hline \multicolumn{1}{c}{ Mga makabagong istratehiya } & Elementarya & Sekundarya \\
\hline Modyular na pamamaraan ng pag-aaral sa mga aralin & 6 & 6 \\
$\begin{array}{l}\text { Pag-gamit ng internet koneksyon para sa birtuwal na pagbibigay } \\
\text { kaalaman at pagturo upang mas malinaw at mapadali ang pag-aaral }\end{array}$ & 4 & 5 \\
ng mga estyudante & & \\
$\begin{array}{l}\text { Pagbase at pagtitiwala sa pag-gamit ng sosyal media upang } \\
\text { makasumiti at makapag-bigay parte ang mga mag-aaral sa kanilang }\end{array}$ & 1 & 1 \\
mga tungkulin bilang isang estyudante & & 3 \\
Limitadong pagkikita-kita ng mga mag-aaral at mga guro $\quad$ Kabuonan & 15 & 15 \\
\hline
\end{tabular}

Ang modular distance learning ay paggamit ng modyul na maaaring nakalimbag o digital na kopya ang ibibigay sa mag-aaral (DepEd LCP, 2020). Ayon kay DepEd Undersecretary Malaluan hindi kailangan ng mag-aaral ng internet o gadget (GMA news, 2020). Ang modyul na ginamit ay isang uri ng self-learning module. Nangingibabaw sa mga guro ang modyular na pamamaraan ng pag-aaral sa mga aralin sapagkat may magandang dulot ito sa mga mag-aaral na mahasa sa pagbabasa nang naiintindan ang binabasang aralin. At ang mga magulang ay nais rin ang uri ng distance learning na ang modular 8.8 milyon magulang ang nagsabi gusto nila ito. Ngunit, kakabit ng magandang dulot ng modyular, may iilan sa mga mag-aaral na mahina sa sariling pag-aaral na kina-kailangan ang aktuwal na pagpa-paliwanag. Sa modyular na pamamaraan, ang departamento ng edukasyon ay makakapag-bahagi o makakatulong na makapagbigay ng mga pangunahing materyales upang maisakatuparan at mas maging epektibo ang pagtataguyod ng edukasyon sa kabila ng pandemyang kinakaharap. Masasabing epekto ang modyular sapagkat ang maraming mag-aaral ang mas ginu-gusto ang modyular na pamamaraan sapagkat sila ay may pagkakataon na makapagnabik aral sa nakaraang aralin upang maging sariwa muli ang mga napag-aralan.

\section{Talahanayan 2}

Iba't-ibang salik na nakakaapekto sa pagtuturo ng akademikong Filipino

\begin{tabular}{lcc}
\multicolumn{1}{c}{ Mga salik na nakakaapekto sa pagtuturo sa akademikong filipino } & Elementarya & Sekundarya \\
\hline Mabagal na signal & 2 & 3 \\
Kakulangan sa kagamitan & 7 & 3 \\
$\begin{array}{l}\text { Kakaposan sa oras at hindi makapag-pokus sa pagsasagawa sa mga } \\
\text { takdang Gawain }\end{array}$ & 4 & 2 \\
$\begin{array}{l}\text { Kawalan ng motibasyon o gana upang ipag-patuloy parin ang } \\
\text { pag-aaral }\end{array}$ & 2 & 15 \\
\hline
\end{tabular}

Ayon sa talahanayan 2, ang labis na nakaka-apekto sa pagtuturo ng akadameking filipino ay ang kakulangan sa kagamitan ng mga mag-aarl sa lipunan. Sapagkat, ang nakararami ay kapos sa pang-araw araw na gastusin at ang mga magulang ay walang regular na painagkakakitaan. Hindi makakaila na dito sa ating lipunan marami ang mahihirap na pamilya, hindi lahat ng mag-aaral ay may kakayahan na makabili ng mga pangunahing pangangailangan sa pag-aaral, katuald ng mga telepono, kompyuter, at marami pang iba na kina-kailangan upang maipag-patuloy padin ang pag-aaral ngayong pandemya. Gayondin sa mga pa-aralan, hindi lahat ay may sapat na kagamitan o materyales katulad ng mga printing materyals na isa sa pangunahing pangagailan. Hindi lahat ng guro ay may sariling kagamitan upang mas masuportahan ang sistema ng eduskasyon natin ngayon. Noon paman, may kakulangan na sa kagamitan sa pag-aaral ng akademikong filipino sa kadahilanang hindi handa ang departamento sa mga bagong.

Makikita sa resulta na marami ang sang-ayon sa rekomendasyon na mas palawakin at bigyan ng sapat na pansin at tuon sa mga pamamaraan na dapat magampanan ng maayos upang mas mapadali sa bawat estyudante at guro ang pag-aaral sa panahong kinakaharap ng nakararami sapagkat ayon sa mga guro, hindi madali ang modyular o birtuwal sa kadahilanang mas mabuti at maayos parin ang nakasanayang tradisyonal na pag-aaral.

4 Consortia Academia Publishing (A partner of Network of Professional Researchers and Educators) 
Talahanayan 3

Rekomendasyon ng mga guro

\begin{tabular}{|c|c|c|}
\hline $\begin{array}{l}\text { Mga rekomandasyong nabuo batay sa pag-aanalisa at resulta ng mga } \\
\text { datos }\end{array}$ & Elementarya & Swkundarya \\
\hline $\begin{array}{l}\text { Mas palawakin at bigyan ng sapat na pansin at tuon sa mga } \\
\text { pamamaraan na dapat magampanan ng maayos upang mas mapadali } \\
\text { sa bawat estyudante at guro ang pag-aaral sa panahong kinakaharap } \\
\text { ng nakararami }\end{array}$ & 9 & 9 \\
\hline $\begin{array}{l}\text { Paglaanan ng sapat na panahon upang mapaghandaan ang bawat } \\
\text { aralin na mas mapadali at mapa-intindi ng walang kakulangan na } \\
\text { kaalaman sa aralin }\end{array}$ & 3 & 4 \\
\hline Magtakda ng panahon o magbigay oras para sa birtuwal na pagtuturo & 1 & 1 \\
\hline $\begin{array}{l}\text { Kinakailangan na mas maipakita ang kagustohan at pagsisikap na } \\
\text { makapag-bigay aral at magkaroon ng malawak napag-intidi sa bawat } \\
\text { isa }\end{array}$ & 2 & 1 \\
\hline Kabuoan & 15 & 15 \\
\hline
\end{tabular}

Nakakaimpluwensya sapag-unawa ng estudyante ang paraang gamit ng guro kaya dapat lang na mabisa ito. Samakatuwid, nakasalalay sa asal at estratehiyang gagamitin ng guro kung makakamtan ang naisniyang maunawaan ng estudyante (Fernandez et al., 2010). Sa ibang banda, nakasalalay pa rin sa estudyante ang pagkatuto at hindi sa titser atpamamaraan ng titser lamang. Nangangailangan ng pagtutulongan at pakiki-isa ng mga magulang, mag-aaral, at mga guro upang mas maging epektibo ang kasulukuyang Sistema ng pag-aaral.

\section{Rekomendasyon}

$>\quad$ Pag tuunan ng pansin ang sulirinaning pang edukasyon; tulong sa mga guro at estudyante patungo sa maayos na edukasyon upang mas mapalawak ang kakayahan na makapaghatid ng kaalaman sa larangan ng edukasyon.

$>\quad$ Pag bibigay ng tamang oras para sa birtuwal na pag aaral upang mas maintindihan ng mag-aaral ang mga araling tinatalakay.

$>\quad$ Pagkakaroon ng maayos na access ng internet sa at pagbibigay ng sapat na kagamitan para sa modyular.at iba pang mga istratehiyang isinasagawa nga mga guro at ng gobyerno.

$>\quad$ Paggawa ng pananaliksik o isang meeting para alamin kung anong klaseng pag aaral ang kaya ng isang estudyante at mas mabigyang linaw ang mga bagay na dapat mapaunlad pa.

$>\quad$ Maayos na komunikasyon sa mga guro sa iba't ibang subseheto upang mas maging epektibo ang pamamaraan na siyang nagbibigay daan upang patuloy na makapag-lingkod ang mga guro at ang mga mag-aarl ay hindi mapag-iwanan ng panhon.

$>\quad$ Pag tutok o pagbibigay-tuon sa mga batang limitado ang kapasidad sa pag aaral at mahina ang kakayahan na maunawaan ang mga aralin ng walang gabay ng mga guro.

$>\quad$ Sapat na oras uapng magabayan ang mga mag-aaral na matuto mula sa mga guro at magulang.

$>\quad$ Solusyon sa mga suliraning kinakaharap at bigyan ng daan na buksan ang mga paaralan

> Maayos na iskedyul sa pag aaral modyular o birtuwal man. Upang magkaroon ng pokus at di naghahabol sa oras ang mga estudyante at guro

$>\quad$ Pagbibigay ng maayos at komportableng opisina para sa mga guro. Para sa mas maayos na birtuwal na pag aaral.

$>\quad$ Pagbibigay ng tamang dami ng modyul para sa mag aaral. Upang mas mapagtuonan ng pansin o kaya naman ay di mawala sa pokus ang mga mag aaral pati na din ang mga guro 
Gile, I., Certiza, M., Medez, M., Aniag, E., \& Gelilio, E.

$>\quad$ Malawak na konsiderasyon lalo na sa mga nag tatrabaho habang nag aaral ngayong modyular o birtuwal naman ang edukasyon.

$>\quad$ Pagbibigay ng sapat na oras para gawin ang mga Gawain. At pagibihay ng takdang panahon sa pagsusumiti ng mgs Gawain na na-aayon sa kakayahan ng mga mag-aaal.

\section{Kongklusyon}

Batay sa pananaliksik, nabuo ang mga sumusunod na konklusyon;

$>\quad$ Ang modyular na pamamaraan ng pag-aaral sa mga aralin ay napatunayan na ito ay epektibo sa pagtuturo ng akademikong filipino. Ito ay isa sa mga makabagong istratehiya na parehong mga magulang at mga guro an nais sa istratehiyang ito sapagkat hindi lamang naisasakatuparan nito na maitaguyod ang pag-aaral ngayong may kinakaharap na pandemya kudi nahahasa rin nito ang mga mag-aaral sa pagbabasa at pag-iintindi sa mga aralin kahit hindi lubos na naipapaliwanag ng mga guro sa personal. Sa modyular na pamamaraan ng pag-aaral sa mga aralin, nasusukat nito ang kakayahan ng mga mag=aaral sap ag-uunawa nh walang gabay ng mga guro sa personal, makikita ang matibay na hangarin ng mga mag-aaral na matuto sa gitna ng pandemyang dinaranas ng lahat.

$>\quad$ Natukoy ang mga salik na nakakaapekto sa pagtuturo ng akademikong Filipino. Hindi maitatanggi na may iilan talagang nakakaapekto sa pagtuturo ngayong pandemya. Naipakita sa pananaliksik na ito kung ano nga ba ang salik na naakakaapekto na makikita sa talahanayan 2. Ang kakulangan sa kagamitan ang mayroon ng pinakamataas na puntos sa elementarya at sekundarya, alam natin na nakakaranas tayo ng kagipitan at kakulangan sa mga kagamitan dahil sa pandemya. Marami ang walang trabaho, at ang agarang sulosyon ay pilit na ipinatupad agad upang maitaguyod ang eduasyon na hindi maitatanggi na ang lahat ay hindi handa at hindi sapat an maikling panahon upang ang lahat ay mabigyan lahat ng agarang pagsuporta at aksyon.

$>\quad$ Ang mga guro ay nagbigay ng rekomendasyon ayon sa kanilang kinakaharap ng pagsubok sa pagtuturo ngayong mayroong pandemya. Bukal sa kanilang kalooban na makapag-bigay ng ideya kung ano-ano pa ng aba ang mga dapat tutukan at gampanan upang mas maging epektibo ang pagtuturo, at tunay na makapagbigay ng kaalaman.

$>\quad$ Naipakita sa pananaliksik na ito na ang hangarin na maitaguyod ang eduskasyon ay hindi basta-basta mapapatigil sapagkat marami ang nakiki-isa at nakikipagtulungan upang patuloy na makahatid ng kaalaman sa mga mag-aarl ang ating mga guro. Lakas loob na hinarap ng mga guro at ang mga kawani ng gobyerno na mabigyang solusyon ang problemang hatid ng pandemya.

> Nagkaroon ng linaw at nabigyan ng pagkakataon na maipakita ang pagsisikap ng mga guro, kagawaran ng departamento ng edukasyon na patuloy na makapag-bahagi ng dekalidad ng kaalaman sa kasagsagan ng pandemya

\section{Talasanggunian}

Boroidan, M. D., Diaz, J. M., Lusabia, A. A., \& Novela, S. B. (2020). Panimulang pananaliksik tungkol sa pinagmulan ng sitwasyong pangwika batay sa isyung pampolitika. Coursehero.com. https://www.coursehero.com/file/73211201/Researchdocx/

Chin, J. M.-C., Ching, G. S., del Castillo, F., Wen, T.-H., Huang, Y.-C., del Castillo, C. D., Gungon, J. L., \& Trajera, S. M. (2022). Perspectives on the barriers to and needs of teachers' professional development in the Philippines during COVID-19. Sustainability, 14(1), 470. https://doi.org/10.3390/su14010470

De Torres, A. V., Halis, M., \& Joven, C. (2022). Epekto ng makabagong teknolohiya sa mga mag-aaral ng senior high school sa ika-labing isang antas. Academia.edu.

https://www.academia.edu/31494651/epekto_ng_makabagong_teknolohiya_sa_mga_mag_aaral_ng_sen

6 Consortia Academia Publishing (A partner of Network of Professional Researchers and Educators) 
Makabagong istratehiya sa pagtuturo ng akademikong Filipino: Pagsilip sa bagong kadawyan

ior_high_school_sa_ika_labing_isang_antas?pop_sutd=false

DepEd: Distance learning does not require gadgets, internet connection. (2020). GMA News Online.

https://www.gmanetwork.com/news/topstories/nation/745397/deped-distance-learning-does-not-require -gadgets-internet-connection/story/

Evangelista, C. (2012). Kahalagahan ng paglinang ng kasanayan sa mabisang pagsasalita. https://www.slideshare.net/iloveyouhtac/pagsasalita

Fernandez, et al. (2010). Mga salik sa epektibong pamamaraan ng pagtuturo sa asignaturang Filipino sa mataas na paaralan ng Palompon Institute of Technology. Academia.edu.

https://www.academia.edu/35833367/Mga_Salik_sa_Epektibong_Pamamaraan_ng_Pagtuturo

The Basic Education Learning Continuity Plan in the Time of COVID-19. (2020). Department of Education. https://www.deped.gov.ph/wp-content/uploads/2020/07/DepEd_LCP_July3.pdf 
Gile, I., Certiza, M., Medez, M., Aniag, E., \& Gelilio, E. 